\title{
Preventing Falls in Physically Active Community-Dwelling Older People: A Comparison of Two Intervention Techniques
}

\author{
Ellen Freiberger ${ }^{\mathrm{a}}$ Hylton B. Menz ${ }^{\mathrm{b}}$ Karim Abu-Omar ${ }^{\mathrm{a}} \quad$ Alfred Rütten $^{\mathrm{a}}$ \\ a Institut für Sportwissenschaft und Sport, Friedrich-Alexander-Universität Erlangen-Nürnberg, Erlangen, Germany; \\ ${ }^{b}$ Musculoskeletal Research Centre, Faculty of Health Sciences, La Trobe University, Bundoora, Australia
}

\section{Key Words}

Accidental falls $\cdot$ Exercise $\cdot$ Fall prevention

\begin{abstract}
Background: Falls are common in physically active older people; however, most intervention studies have been targeted at frail older people. Objective: To evaluate the effectiveness of two intervention techniques for preventing falls in physically active community-dwelling older people. Methods: Two hundred and seventeen people (120 men and 97 women) aged between 70 and 90 years recruited from a health insurance company membership database were randomly allocated to receive either a psychomotor intervention focusing on body awareness, body experience and coordination, a fitness intervention focusing on functional skills, strength, endurance and flexibility, or no intervention (control group). The outcome measures were prospective falls (number of fallers, number of multiple fallers, number of falls and falls rate) and measures of physical performance (Timed Up and Go Test, maximal step length, sit-to-stand time, normal and fast walking speed). Results: At the 4month follow-up, significant improvements in the Timed Up and Go Test and sit-to-stand times were observed for both the psychomotor and fitness intervention groups. During the 12-month follow-up period, $39 \%$ of the participants fell at least once, and $19 \%$ fell on multiple occasions. The pro-
\end{abstract}

portion of fallers in the fitness intervention group was $23 \%$ less than in the control group ( $\mathrm{RR}=0.77,95 \% \mathrm{Cl} 0.60-0.97$ ), but no significant reduction in falls was observed in the psychomotor intervention group. Conclusion: A fitness training program improves some aspects of physical performance and reduces falls by $23 \%$ in physically active older people.

Copyright $\odot 2007$ S. Karger AG, Basel

\section{Introduction}

Falls in older people are a major public health problem, with 1 in 3 people aged 65 and over falling each year [1, 2]. Falls are the leading cause of injury-related hospital admissions in older people, accounting for $4 \%$ of all hospital admissions in this age group [3]. Prevention of falls and subsequent disability is therefore a key priority area in geriatric rehabilitation [4].

Several recent community-based studies have indicated that various forms of exercise, such as Tai Chi, group exercise and home-based exercise can reduce falls by approximately $30-40 \%[5,6]$. Overall, exercise interventions appear to be most effective when targeted to highrisk older people, such as those with strength and balance deficits, those aged over 80 and those with multiple falls risk factors [5, 6]. It has been suggested that interventions that have failed to show a significant reduction in falls are

\section{KARGER}

Fax +4161306 1234

E-Mail karger@karger.ch

www.karger.com
(C) 2007 S. Karger AG, Basel

0304-324X/07/0535-0298\$23.50/0

Accessible online at:

www.karger.com/ger
Dr. Ellen Freiberger, Institut für Sportwissenschaft und Sport

Friedrich-Alexander-Universität Erlangen-Nürnberg

Gebbertstrasse 123b, DE-91058 Erlangen (Germany)

Tel. +49 9131852 5005, Fax +499131852 5002

E-Mail ellen.freiberger@sport.uni-erlangen.de 
those that have been targeted at people with too low a physiological risk of falling $[7,8]$. However, given that falls are also common in vigorous older people due to their increased exposure to hazardous situations $[1,9]$, it could be that the programs were not appropriate for this particular subgroup. For example, a physically active older person may have little to gain from a low-level strength training program, but may benefit from an intervention designed to enhance body awareness and modify behavior.

Therefore, the aim of this study was to evaluate the effectiveness of two different interventions in preventing falls in a sample of physically active community-dwelling older people. It was hypothesized that an intervention program incorporating psychomotor aspects of body awareness, coordination and behavioral training would be more effective at reducing falls in this population compared to an intervention focusing on health-related fitness.

\section{Methods}

\section{Participants and Recruitment}

The study population consisted of community-dwelling people aged 70 years and older living in Erlangen, Germany. Participants were drawn from a health insurance company membership database $(n=2,468)$. Participants were excluded if they were unable to walk independently, were under 70 years of age or had cognitive impairment (defined in the Neuropsychological Ageing Inventory as either a digital symbol substitution test score of less than 25 or a number connecting test, similar to trail-making A, score of greater than $1 \mathrm{~min}$ ) [10].

Figure 1 shows the recruitment process. The study was undertaken in two phases. Firstly, the membership database was randomized using stratified random sampling to ensure equal numbers of men and women and equal distribution across age-groups. In phase 1, the first 1,000 people were selected from the randomized database. Each of these people was then contacted by letter and invited to take part in the study. Of the 1,000 people contacted, 102 (10\%) agreed to take part, and of these, 83 met the inclusion criteria. These participants formed the control group. In phase 2, the next 1,000 people were selected from the list. Of these, 139 (14\%) agreed to take part, 134 of whom met the inclusion criteria. These participants were then randomly allocated into either the psychomotor or fitness intervention groups. The study protocol was developed in accordance with the Prevention of Falls Network Europe (PROFANE) guidelines [11] and written informed consent was obtained from all participants.

\section{Measurements}

Demographic, Health, and Physical Activity Characteristics

Demographic factors (such as age, gender, education and income), medical conditions and number of medications were obtained via a structured questionnaire. Overall health status was documented using the brief version of the World Health Organi- zation Quality of Life questionnaire [12], with higher scores indicating better health (range 0-100). Physical activity levels were documented using an objective measure of walking speed (WS) over $8 \mathrm{~m}$, and self-reported number of hours walked per week. History of falls in the past 6 months was also documented.

Physical Performance Measures

Four measures were used to evaluate the effects of the intervention on physical performance.

For the Timed Up and Go (TUG) Test, participants were given verbal instructions to stand up from a chair, walk $3 \mathrm{~m}$ as quickly and as safely as possible, turn around a coin placed on the floor, walk back, and sit down. Participants were asked to complete three trials under three conditions: performance of the TUG alone, performance of the TUG with the addition of a cognitive task (counting backwards by threes), and performance of the TUG with the addition of an upper-extremity motor task (carrying a full cup of water). TUG was defined as the sum of the time taken (in seconds) to complete the three conditions [13]. For the maximal step length (MSL) test, participants were instructed to step forwards maximally with one leg, maintaining the stance leg in the initial position, and then return to their initial stance position in a single step. MSL was defined as the average step length (measured in $\mathrm{cm}$ ) over a series of three trials [14]. For the sit-tostand (STS) test, participants were asked to rise from a standard height chair $(43 \mathrm{~cm})$ five times as quickly and safely as possible with their arms folded across their chests. STS was defined as the total time taken in seconds to complete the task [15]. WS was measured at self-selected normal and fast speeds over a 10-meter distance, ignoring the first and the last meter to exclude acceleration and deceleration steps. WS (normal) and WS (fast) were documented in meters per second. Each of these tests was selected as they have been shown to be useful indicators of physical performance and are capable of differentiating between fallers and nonfallers [16-19]. The assessors undertaking the physical performance tests were blinded to group allocation.

\section{Interventions}

There were two interventions in the study, each comprising 32 sessions (2 sessions/week) of 1-hour duration over a 16-week period. Group discussions were conducted at the beginning and end of each session to outline the goals of the program and to review progress. Participants in both intervention groups were instructed to perform selected exercises from the program at home on a daily basis between sessions and following the completion of the 16 week intervention period. The control group received no intervention. At the end of the 12-month follow-up period, control participants were invited to participate in the intervention classes.

The Psychomotor Intervention

The psychomotor intervention was based on the Gestaltkreis [20] and Salutogenese [21] models and focused on improving the interaction between perception and action. The intervention consisted of strength training (including the use of dumbbells, ankle weights and weight-bearing exercises), balance training (including standing balance, dynamic weight transfers and stepping strategies), motor coordination training (including motor control when performing ADLs, motor control under time pressure and sensory awareness), competence training (including social com- 


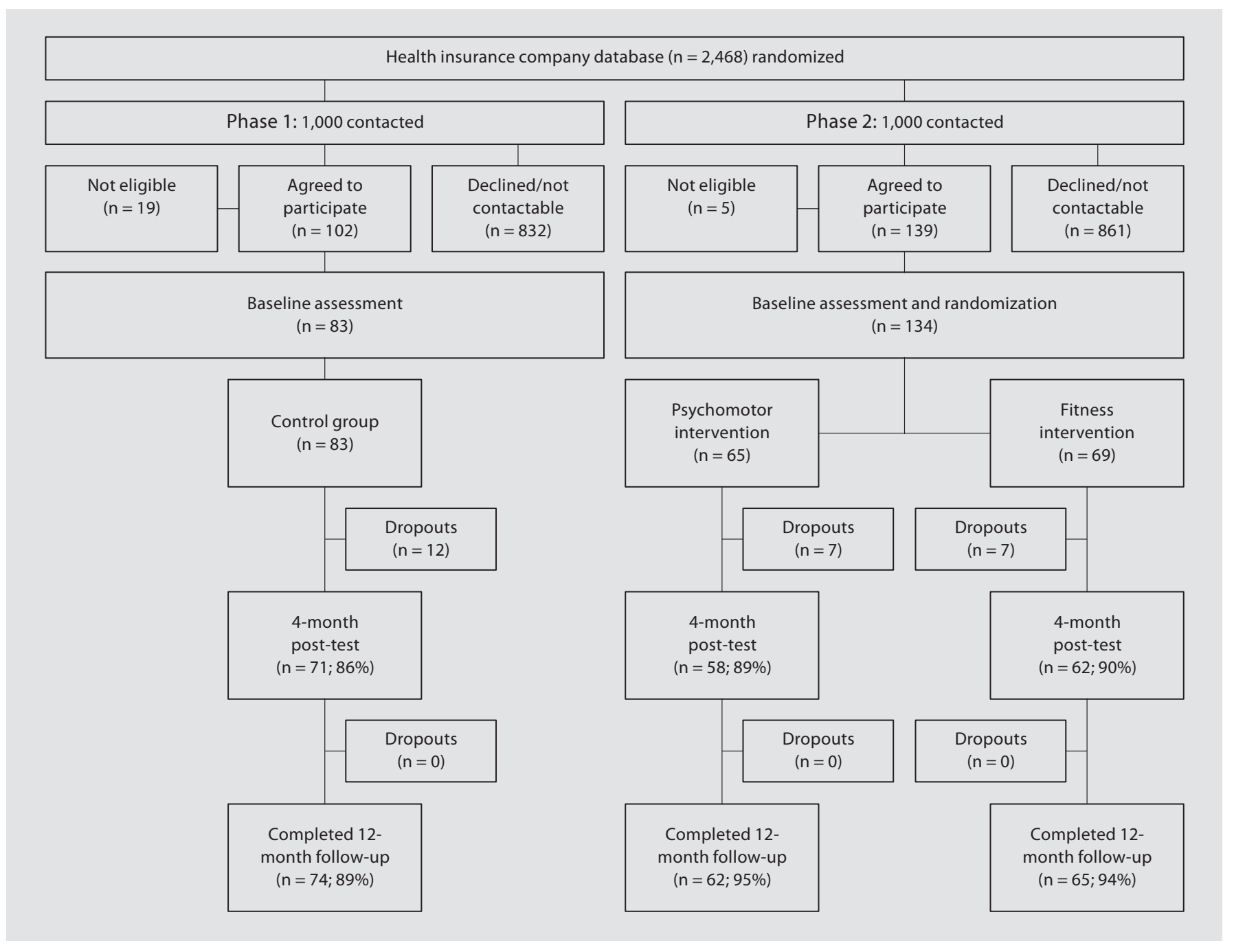

Fig. 1. Flow chart of participants through the study.

petence, material competence and enhancing identity) and perceptual training (including body orientation and space perception). The approximate breakdown of the time spent on each of these components was: strength training (20\%), balance training (20\%), motor coordination (30\%), competence training (15\%) and perceptual training (15\%).

The Fitness Intervention

The fitness intervention primarily focused on physical health resources (such as strength, endurance and flexibility) and incorporated both group and home-based exercises as well as physical activity recommendations. The intervention consisted of strength and flexibility training (including the use of dumbbells, ankle weights, weight-bearing exercises and joint flexibility), balance and motor coordination training (including standing balance, dynamic weight transfers, stepping strategies, motor control when performing ADLs, motor control under time pressure and sensory awareness) and endurance training (including normal walking and Nordic walking). The approximate breakdown of the time spent on each of these components was: strength and flexibility training $(33 \%)$, balance and motor coordination training (33\%), and endurance training (33\%).

\section{Falls Surveillance}

Falls were defined as 'an unexpected event in which the participant comes to rest on the ground, floor, or at a lower level' [11]. Falls were monitored for 12 months. When a fall occurred, specific details about fall injuries were obtained through structured telephone interviews. If falls calendars were not returned at the end of each month, follow-up telephone calls were made.

\section{Statistical Analysis}

The data were analyzed using SPSS v13.0 (SPSS Corp., Chicago, Ill., USA) and STATA 8 (Stata Corp., College Station, Tex., USA) statistical software. The continuous physical performance measures at the 4-month follow-up were compared using analysis of 
Table 1. Demographic, health, and physical activity characteristics of the study population at baseline

\begin{tabular}{lcccc}
\hline Variable & $\begin{array}{l}\text { Psychomotor } \\
\text { intervention } \\
(\mathrm{n}=65)\end{array}$ & $\begin{array}{l}\text { Fitness } \\
\text { intervention } \\
(\mathrm{n}=69)\end{array}$ & Control group & Total sample \\
& & $\mathrm{n}=83)$ & $(\mathrm{n}=217)$ \\
\hline Demographic factors & $76.4 \pm 4.2$ & $75.4 \pm 3.8$ & $76.5 \pm 3.9$ & $75.9 \pm 4.0$ \\
Age & $31(48)$ & $27(39)$ & $39(47)$ & $97(45)$ \\
Females & $18(28)$ & $33(33)$ & $25(29)$ & $76(35)$ \\
Tertiary education & $3,530 \pm 1,490$ & $4,090 \pm 1,610$ & $3,900 \pm 1,830$ & $3,840 \pm 1,659$ \\
Income, EUR per month & $2.4 \pm 1.6$ & $2.0 \pm 1.4$ & $2.1 \pm 1.6$ & $2.3 \pm 1.6$ \\
Medical conditions & $19(29)$ & $25(36)$ & $30(36)$ & $74(34)$ \\
Number of diagnosed conditions & $6(9)$ & $6(9)$ & $9(11)$ & $21(10)$ \\
Osteoarthritis & $18(28)$ & $18(26)$ & $27(30)$ & $63(29)$ \\
Osteoporosis & $6(9)$ & $2(3)$ & $4(5)$ & $12(6)$ \\
Cardiovascular disease & $3(5)$ & $1(1)$ & $5(6)$ & $9(4)$ \\
Diabetes & $3.1 \pm 2.3$ & $2.9 \pm 2.5$ & $3.4 \pm 2.4$ & $3.2 \pm 2.4$ \\
Depression & $72.8 \pm 14.0$ & $76.0 \pm 13.1$ & $69.9 \pm 17.3$ & $72.9 \pm 14.9$ \\
Number of medications & & & & \\
WHOQOL Brief overall & $1.3 \pm 0.3$ & $1.4 \pm 0.3$ & $1.3 \pm 0.3$ & $1.3 \pm 0.3$ \\
Physical activity & $10.3 \pm 8.8$ & $10.2 \pm 10.0$ & $8.7 \pm 9.2$ & $9.8 \pm 9.3$ \\
Walking speed, m/s & $24(37)$ & $27(39)$ & $24(29)$ & $75(35)$ \\
Walking, h/week & & & & \\
Fallen in past 6 months & & & & \\
\hline
\end{tabular}

Values are expressed as mean \pm standard deviation or $\mathrm{n}(\%)$.

covariance with baseline scores and intervention group entered as independent variables [22]. An intention to treat approach was used for missing physical performance data, in which the last observed response was carried forwards [23]. If continuous data were found to be skewed, logs of the scores were computed and statistical testing was carried out on the more normally distributed variables. Consistent with the recommendations of the PROFANE group [11], four falls outcomes were used: the number of fallers, the number of multiple fallers, the rate of falls, and the time to first fall. The number of fallers and multiple fallers (two or more falls) were compared by calculating relative risks (RR). The number of falls and falls rate per person per year in the four groups were compared using negative binomial regression models. The incident rate ratio with corresponding $95 \%$ confidence intervals was calculated for each intervention group relative to the control group. This approach takes into account all falls and adjusts for varying duration of follow-up $[24,25]$. Time to first fall, as a safety measure, was analyzed using Kaplan-Meier survival analysis.

\section{Results}

\section{Demographic, Health, and Physical Activity}

Characteristics at Baseline

Table 1 shows the baseline demographic, health and physical activity characteristics for the three groups and the total sample. Overall, the sample was highly educat- ed, had higher than average income levels, very good selfreported health and higher than average levels of physical functioning. Baseline measurements were similar across the intervention groups, although the TUG and MSL were slightly worse in the control group.

\section{Intervention Compliance and Participant Retention}

The number of sessions offered for each of the interventions was 32 . The median number of sessions attended for the psychomotor intervention was 26 (range 0-32) and for the fitness intervention it was 26 (range $0-32$ ). At least $50 \%$ of sessions were attended by $82 \%$ of participants in the psychomotor group and $84 \%$ of participants in the fitness group. Figure 1 shows the number of participants in each of the intervention groups throughout the study period. The percentage of participants who undertook both baseline and 4-month physical performance testing was $89 \%$ for the psychomotor intervention, $90 \%$ for the fitness intervention and $86 \%$ for the control group. The percentage of participants who completed the 12-month falls follow-up was $95 \%$ for the psychomotor intervention, $94 \%$ for the fitness intervention, and $89 \%$ for the control group. There were no adverse events. 
Table 2. Baseline and 4-month scores for the physical performance measures in each of the intervention groups

\begin{tabular}{|c|c|c|c|c|c|c|}
\hline \multirow[t]{2}{*}{ Variable } & \multicolumn{2}{|c|}{ Psychomotor intervention $(\mathrm{n}=65)$} & \multicolumn{2}{|c|}{ Fitness intervention $(n=69)$} & \multicolumn{2}{|c|}{ Control group $(\mathrm{n}=83)$} \\
\hline & baseline & 4-month & baseline & 4-month & baseline & 4-month \\
\hline $\mathrm{TUG}^{\mathrm{a}}, \mathrm{s}$ & $29.5 \pm 8.0$ & $27.1 \pm 6.1^{\mathrm{b}, \mathrm{d}}$ & $28.9 \pm 8.5$ & $25.7 \pm 7.6^{b, c}$ & $30.6 \pm 9.6$ & $29.8 \pm 8.6^{c, d}$ \\
\hline MSL, cm & $60.5 \pm 17.1$ & $68.1 \pm 15.5$ & $54.7 \pm 18.4$ & $67.8 \pm 17.8$ & $49.4 \pm 20.9$ & $57.2 \pm 17.5$ \\
\hline STS time ${ }^{\mathrm{a}}, \mathrm{s}$ & $12.1 \pm 4.9$ & $11.3 \pm 2.8^{\mathrm{b}}$ & $12.3 \pm 3.8$ & $11.1 \pm 3.5^{\mathrm{b}}$ & $13.3 \pm 4.3$ & $13.4 \pm 4.4^{\mathrm{c}, \mathrm{d}}$ \\
\hline \multicolumn{7}{|l|}{$\mathrm{WS}, \mathrm{m} / \mathrm{s}$} \\
\hline Normal & $1.3 \pm 0.3$ & $1.3 \pm 0.2$ & $1.4 \pm 0.3$ & $1.4 \pm 0.2$ & $1.3 \pm 0.3$ & $1.3 \pm 0.3$ \\
\hline Fast & $1.8 \pm 0.3$ & $1.8 \pm 0.3$ & $1.7 \pm 0.3$ & $1.8 \pm 0.3$ & $1.7 \pm 0.3$ & $1.7 \pm 0.3$ \\
\hline
\end{tabular}

${ }^{a}$ Overall significant difference between the groups $(\mathrm{p}<0.05)$.

${ }^{\mathrm{b}}$ Post-hoc tests on adjusted 4-month scores significantly different to the control group $(\mathrm{p}<0.05)$.

${ }^{c}$ Post-hoc tests on adjusted 4-month scores significantly different to the psychomotor group ( $\left.\mathrm{p}<0.05\right)$.

${ }^{\mathrm{d}}$ Post-hoc tests on adjusted 4 -month scores significantly different to the fitness group $(\mathrm{p}<0.05)$.

Table 3. Falls during the 12-month follow-up

\begin{tabular}{llllll}
\hline & $\begin{array}{l}\text { Control } \\
\text { group }\end{array}$ & $\begin{array}{l}\text { Psychomotor } \\
\text { intervention }\end{array}$ & RR $(95 \% \mathrm{CI})^{\mathrm{a}}$ & $\begin{array}{l}\text { Fitness } \\
\text { intervention }\end{array}$ & ${\text { RR }(95 \% \mathrm{CI})^{\mathrm{b}}}$ \\
\hline Fallers, n (\%) & $37(45)$ & $29(45)$ & $1.00(0.75-1.34)$ & $19(28)$ & $0.77(0.60-0.97)$ \\
Multiple fallers, n (\%) & $19(23)$ & $15(23)$ & $1.00(0.84-1.20)$ & $8(12)$ & $0.87(0.75-1.01)$ \\
Falls, n (rate) & $87(1.04)$ & $79(1.22)$ & $0.92(0.59-1.45)$ & $62(0.90)$ & $0.64(0.38-1.06)$ \\
\hline
\end{tabular}

${ }^{a}$ Psychomotor intervention vs. control group. ${ }^{b}$ Fitness intervention vs. control group.

\section{Physical Performance Outcomes}

Table 2 shows the baseline and 4-month scores for each of the physical performance measures in each of the groups. At 4 months, there were significant differences between the groups for TUG time $\left(\mathrm{F}_{2}=3.5, \mathrm{p}=0.040\right)$, with post-hoc tests indicating that participants in the psychomotor intervention and the fitness intervention both had significantly lower STS times compared to the control group, with the greatest reduction observed in the fitness intervention group. There were also significant differences between the groups for STS time at 4 months $\left(\mathrm{F}_{2}=5.2, \mathrm{p}<0.001\right)$, with post-hoc tests indicating that participants in the psychomotor intervention and the fitness intervention both had significantly lower STS times compared to the control group. There were no significant differences between the groups for MSL, WS (normal) or WS (fast).

\section{Falls}

During the 12-month follow-up period, there were 228 falls. A surprisingly large number of falls involved vigorous activities such as skiing ( 25 falls) and cycling (15 falls). Table 3 shows the number of fallers, multiple fallers, falls and falls rate in each of the intervention groups. The proportion of fallers in the fitness intervention group was significantly lower (23\%) than in the control group $(\mathrm{RR}=0.77,95 \% \mathrm{CI} 0.60-0.97)$. There was also a $13 \%$ reduction in the number of multiple fallers and a $46 \%$ reduction in the falls rate in the fitness intervention group which approached statistical significance. No significant reduction in falls was noted in the psychomotor intervention group. Figure 2 shows the Kaplan-Meier plot for time to first fall for the three intervention groups. A clear separation of the fitness group was evident throughout the duration of the 12-month follow-up period. The mean time to first fall was $216 \pm 15$ days in the control group, $281 \pm 16$ days in the psychomotor group, and $337 \pm 9$ days in the fitness intervention group. 


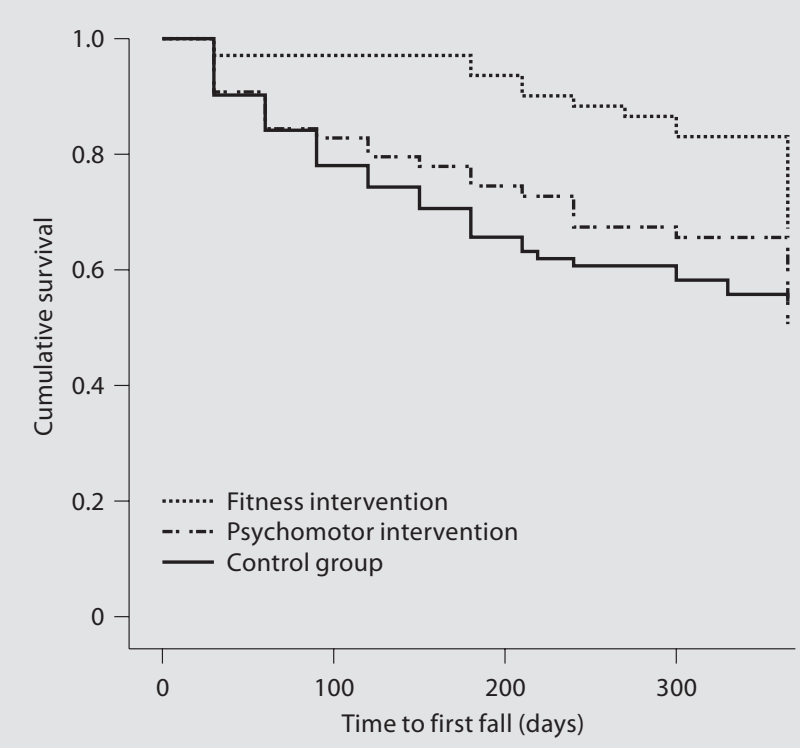

Fig. 2. Time to first fall in the three intervention groups.

\section{Discussion}

The objective of this study was to examine the effectiveness of two intervention techniques for preventing falls in physically active older people residing in the community. The population recruited for the study was highly educated, had higher than average income levels, very good self-reported health and higher than average levels of physical functioning. Baseline measures indicated better performances than those previously reported for STS [26] and WS [27] in community samples of a similar age. This clearly influenced the type of falls that were documented in the 12-month follow-up, with a large proportion involving sporting activities such as skiing (25 falls) and cycling (15 falls). The findings indicate that during the 12 -month follow-up period, there were $23 \%$ less fallers in the fitness intervention group compared to the control group. There was also a trend towards a reduction in the number of multiple fallers and the rate of falls in the fitness intervention group. However, no reduction in falls was observed in the psychomotor intervention group.

Both interventions resulted in small but statistically significant improvements in TUG and STS times, with the fitness intervention group improving slightly more than the psychomotor intervention group in the TUG. These findings are consistent with previous reports of improved TUG $[28,29]$ and STS $[8,30,31]$ following a range of exercise programs. The improvement in both TUG and STS in the fitness intervention group is likely to be due to the focus of this intervention on enhancing strength and endurance of the lower limb muscles. The improvement in the psychomotor intervention group, however, was unexpected, as this intervention had only a small strength training component. It is possible that the other components of the psychomotor program (such as spatial awareness and perception) were responsible for improved TUG and STS times, as it has recently been shown that TUG is associated with an overall measure of physiological falls risk (which included visual and sensory measures) [32], and that STS performance depends not only on lower limb strength, but also on proprioception and psychological status [26].

Despite the improvements in physical performance in the psychomotor group, our initial hypothesis - that the psychomotor intervention would be more effective at reducing falls than the fitness training program - was not supported by the results. We expected that because the group we studied was physically active, they would have little to gain from the fitness program, but would benefit from an intervention focusing on body awareness and coordination. The results indicate that even in a physically active group of older people, an exercise program focusing on strength and balance can further improve physical performance and prevent some falls. Our results do not suggest that strength training is superior to balance training. Rather, our findings indicate that the level of intensity of an exercise intervention is the key factor in reducing falls in a high-functioning cohort. It is possible that the duration of the study was insufficient to demonstrate an effect of the psychomotor intervention, as many of the objectives of this intervention require modification of behavior, which may take longer to achieve than improvements in physical performance. However, confirmation of this hypothesis would require longer term follow-up.

Compared to the reductions in falls observed in previous exercise studies, the $23 \%$ reduction in the number of fallers in the fitness group reported here is relatively modest, and although there was a trend towards less multiple fallers and a lower falls rate, this did not reach statistical significance. However, most studies reporting larger reductions in falls have focused on frailer populations [5, 6]. Furthermore, we adopted the recommendation of the PROFANE group by including all falls in our definition [11], whereas other studies have specifically excluded falls that resulted from external perturbations or overwhelming hazards [33]. It is possible that the fall reduction in our study would have been larger if a more selective def- 
inition was used, as falls related to vigorous activities such as skiing and cycling may not be as amenable to prevention as those that occur when undertaking activities of daily living. In particular, it is likely that a greater reduction in the total number of falls would have been observed, as a large proportion of participants who fell while undertaking sporting activities fell on multiple occasions. However, undertaking this subgroup analysis was not planned a priori and the sample size is probably insufficient to detect differences in the incidence of nonsport-related falls.

The major strengths of this study are the use of a high functioning cohort with a large proportion of men, and the high level of compliance with the interventions. However, the findings need to be viewed in light of study design limitations. Due to logistical reasons, the study had to be undertaken in two phases, with phase 1 involving the selection of the control group, and phase 2 involving randomization into either the psychomotor or fitness intervention groups. Therefore, comparisons between the two intervention groups recruited in phase 2 were made to the control group recruited in phase 1. Although the participants were drawn from the same population and the groups were equivalent at baseline, it is acknowledged that the control group was not recruited at the same time as the psychomotor or fitness intervention groups. Furthermore, each of the interventions consisted of multiple components targeting several falls risk factors, so it is difficult to delineate which specific aspects of the intervention were responsible for the observed improvement in physical performance and reduction in falls. Finally, the generalizability of the study findings to the broader elderly population may be limited, as participants were recruited from a private health insurance database and the participation rate was relatively low (10-15\%).

In conclusion, the findings of this study indicate that a fitness program focusing on functional skills, strength, endurance and flexibility improves some aspects of physical performance and is moderately effective in reducing falls in physically active older people living in the community. A psychomotor intervention focusing body awareness, coordination and behavioral training also improves physical performance but has no effect on falls. Longer term follow-up may be required to adequately evaluate interventions which aim to reduce falls through behavioral modifications, particularly in older people who are physically active.

\section{Acknowledgments}

The Robert Bosch Foundation and Siemens Health Insurance supported this project. Prof. Menz is currently NHMRC Australian Clinical Research Fellow (ID: 433049).

\section{References}

1 O’Loughlin JL, Robitaille Y, Boivin JF, Suissa $S$ : Incidence of and risk factors for falls and injurious falls among the community-dwelling elderly. Am J Epidemiol 1993;137:342354

2 Gill T, Taylor AW, Pengelly A: A populationbased survey of factors relating to the prevalence of falls in older people. Gerontology 2005;51:340-345.

3 Baker SP, Harvey AH: Fall injuries in the elderly. Clin Geriatr Med 1985;1:501-512.

4 American Geriatrics Society, British Geriatrics Society and American Academy of Orthopedics Surgeons Panel on Falls Prevention: Guideline for the prevention of falls in older persons. J Am Geriatr Soc 2001;49: 664-672.

5 Sherrington C, Lord SR, Finch CF: Physical activity interventions to prevent falls among older people: update of the evidence. J Sci Med Sport 2004;7:S43-S51.
6 Gillespie LD, Gillespie WJ, Robertson MC, Lamb SE, Cumming RG, Rowe BH: Interventions for preventing falls in elderly people. Cochrane Database Syst Rev 2003;4: CD000340.

7 Barnett A, Smith B, Lord SR, Williams M, Baumand A: Community-based group exercise improves balance and reduces falls in atrisk older people: a randomised controlled trial. Age Ageing 2003;32:407-414.

8 Lord SR, Tiedemann A, Chapman K, Munro B, Murray SM, Sherrington C: The effect of an individualized fall prevention program on fall risk and falls in older people: a randomized, controlled trial. J Am Geriatr Soc 2005;53:1296-1304.

9 Speechley M, Tinetti M: Falls and injuries in frail and vigorous community elderly persons. J Am Geriatr Soc 1991;39:46-52.

10 Oswald WD: Neuropsychological Ageing Inventory (NAI). Göttingen, Hogrefe and Huber, 2006.
11 Lamb SE, Jorstad-Stein EC, Hauer K, Becker C; Prevention of Falls Network Europe and Outcomes Consensus Group: Development of a common outcome data set for fall injury prevention trials: the Prevention of Falls Network Europe consensus. J Am Geriatr Soc 2005;53:1618-1622.

12 The WHOQOL Group: The World Health Organization Quality of Life assessment (WHOQOL): position paper from the World Health Organization. Soc Sci Med 1995;41: 1403-1409.

13 Shumway-Cook A, Brauer S, Woollacott M: Predicting the probability for falls in community-dwelling older adults using the Timed Up \& Go Test. Phys Ther 2000;80: 896-903.

14 Medell JL, Alexander NB: A clinical measure of maximal and rapid stepping in older women. J Gerontol A Biol Sci Med Sci 2001; 56A:M627-M632. 
15 Csuka M, McCarty DJ: Simple method for measurement of lower extremity muscle strength. Am J Med 1985;78:77-81.

16 Nevitt MC, Cummings SR, Kidd S, Black D: Risk factors for recurrent nonsyncopal falls. A prospective study. JAMA 1989;261:26632668.

17 Lipsitz LA, Jonsson PV, Kelley MM, Koestner JS: Causes and correlates of recurrent falls in ambulatory frail elderly. J Gerontol A Biol Sci Med Sci 1991;46:M114-M122.

18 Campbell AJ, Borrie MJ, Spears GF: Risk factors for falls in a community-based prospective study of people 70 years and older. J Gerontol A Biol Sci Med Sci 1989;44:M112M117.

19 Cho B-L, Scarpace D, Alexander NB: Tests of stepping as indicators of mobility, balance and fall risk in balance-impaired older adults. J Am Geriatr Soc 2004;52:11681173.

20 Brunnhuber S: Gestalt theory of V. V. Weizsacker from the viewpoint of the psychology of emotions. Fortschr Neurol Psychiatr 2001; 69:322-329.

21 Antonovsky A: Health, Stress and Coping: New Perspectives on Mental and Physical Wellbeing. San Francisco, Jossey-Bass, 1979.
22 Vickers AJ, Altman DG: Analysing controlled trials with baseline and follow up measurements. BMJ 2001;323:1123-1124.

23 Hollis F, Campbell S: What is meant by intention to treat analysis? Survey of published randomised controlled trials. BMJ 1999;319: 670-674.

24 Byers AL, Allore H, Gill TM, Peduzzi PN Application of negative binomial modeling for discrete outcomes. A case study in aging research. J Clin Epidemiol 2003;56:559564.

25 Robertson MC, Campbell AJ, Herbison P: Statistical analysis of efficacy in falls prevention trials. J Gerontol A Biol Sci Med Sci 2005;60A:M530-M534.

26 Lord SR, Murray SM, Chapman K, Munro B, Tiedemann A: Sit-to-stand performance depends on sensation, speed, balance, and psychological status in addition to strength in older people. J Gerontol A Biol Sci Med Sci 2002;57:M539-M543.

27 Tiedemann A, Sherrington C, Lord SR: Physiological and psychological predictors of walking speed in older community-dwelling people. Gerontology 2005;51:390-395.

28 Hess JA, Woollacott M: Effect of high-intensity strength-training on functional measures of balance ability in balance-impaired older adults. J Manipulative Physiol Ther 2005;28:582-590.
29 Vaillant J, Vuillerme N, Martigne P, CaillatMiousse J-L, Parisot J, Nougier V, Juvin R: Balance, aging, and osteoporosis: effects of cognitive exercises combined with physical therapy. Joint Bone Spine 2006;73:414-418.

30 Sherrington C, Lord SR, Herbert RD: A randomized controlled trial of weight-bearing versus non-weight-bearing exercise for improving physical ability after usual care for hip fracture. Arch Phys Med Rehabil 2004; 85:710-716.

31 Helbostad JL, Sletvold O, Moe-Nilssen R: Effects of home exercises and group training on functional abilities in home-dwelling older persons with mobility and balance problems. A randomized study. Aging Clin Exp Res 2004;16:113-121.

32 Whitney JC, Lord SR, Close JC: Streamlining assessment and intervention in a falls clinic using the Timed Up and Go Test and Physiological Profile Assessments. Age Ageing 2005;34:567-571.

33 Hauer K, Lamb SE, Jorstad EC, Todd C, Becker C; PROFANE-Group: Systematic review of definitions and methods of measuring falls in randomised controlled fall prevention trials. Age Ageing 2006;35:5-10. 